\title{
Prioritizing Patient Assessment Data (PAD) Using the Japanese Psychiatric Nursing Assessment Classification System (PsyNACS) C)
}

\author{
Hirokazu Ito', Misao Miyagawa ${ }^{2}$, Kazuhiro Ozawa ${ }^{3}$, Tetsuya Tanioka ${ }^{1}$, \\ Yuko Yasuhara ${ }^{1}$, Mutsuko Kataoka4, Beth King5, Masahito Tomotake1, \\ Yumi Kuwamura1, Rozzano C. Locsin'1 \\ ${ }^{1}$ Department of Nursing, Institute of Biomedical Sciences, Tokushima University, Tokushima, Japan \\ ${ }^{2}$ Department of Nursing, Faculty of Health and Welfare, Tokushima Bunri University, Tokushima, Japan \\ ${ }^{3}$ Nursing Collaboration Center, Gifu College of Nursing, Gifu, Japan \\ ${ }^{4}$ Mifune Hospital, Kagawa, Japan \\ ${ }^{5}$ Christine E. Lynn College of Nursing, Florida Atlantic University, Boca Raton, FL, USA \\ Email: "tanioka.tetsuya@tokushima-u.ac.jp
}

Received 5 April 2016; accepted 2 July 2016; published 5 July 2016

Copyright (C) 2016 by authors and Scientific Research Publishing Inc.

This work is licensed under the Creative Commons Attribution International License (CC BY). http://creativecommons.org/licenses/by/4.0/

(c) (7) Open Access

\section{Abstract}

The study identified priorities of the Patient Assessment Data (PAD) using the Japanese Psychiatric Nursing Assessment Classification System (PsyNACS $@$ ) derived from 644 psychiatric nurses' responses who were practicing in specific units: Acute Care Units (ACU), General Care Units (GCU), Long-term Care Units (LCU), physically Complicated Disease Care Units (CDCU), and Dementia Care Units (DCU). Secondary analysis of the PsyNACS $\odot$ on-line survey data using four levels of "importance" was used to determine the priorities: 1) unnecessary; 2) quite important; 3) important and 4) very important. The Mean Factor Points (MFP) and the Welch's ANOVA were calculated. PsyNACS $\subseteq$ score of 3 or higher indicates the PAD as priority. The results showed that in the ACU PAD1, "Psychological symptom", "Stress coping", and "Mood disorder and aggression", and PAD2 "Information of adherence", and "Information of the psychiatry rehabilitation", and PAD7 "Situation of the family and social life", "Relationship to the health care providers", and "Relationships with others" are high priority (high importance). Other PADs showed results below PsyNACS $\odot$ score of 3. The GCU had PAD 3 "Balance of water", the LCU had PAD 4 "Intention/Point of view", and "Thoughts of the patient" and PAD 7 "Disease and family". The CDCU showed PAD 2 "Blood test", PAD 3 "Excretion situation", and PAD 5 "General health condition", "Respiratory and chest symp-

\footnotetext{
${ }^{*}$ Corresponding author.
}

How to cite this paper: Ito, H., Miyagawa, M., Ozawa, K., Tanioka, T., Yasuhara, Y., Kataoka, M., King, B., Tomotake, M., Kuwamura, Y. and Locsin, R.C. (2016) Prioritizing Patient Assessment Data (PAD) Using the Japanese Psychiatric Nursing Assessment Classification System (PsyNACS) @. Open Journal of Psychiatry, 6, 218-227.

http://dx.doi.org/10.4236/ojpsych.2016.63027 
tom", and "Vital signs", and the DCU had PAD 1 "Cognition function", and "Delirium and derangement capacity to register failure", PAD 3 "Function of eating", PAD 6 "Egestion and cleanliness" and PAD 8 "Activity and sleeping", and "Mobility capability". These classifications indicated levels of importance in the CAD comprising the PAD below the score of "2". Japanese psychiatric hospitals specify assessments according to functional areas. By prioritizing the CAD for each PAD, more effective and efficient assessments can be performed according to practice unit.

\title{
Keywords
}

\author{
PsyNACS $@$, Nursing Database, Priority Nursing Assessment Items, Unit Function, Psychiatric \\ Hospital
}

\section{Introduction}

In the psychiatric health care environment of Japan, the average hospital stay is much longer than those of other countries. Long-term hospitalization is a problem in psychiatric hospitals in Japan [1]. Today, the Japanese government is promoting outreach services [2], and patient transitions from hospital to community as social rehabilitation strategy [3]. This situation is essential to prevent re-admissions and early discharge of patients, and to provide appropriate treatments and interdisciplinary care to patients with psychiatric disorders. However, there is no patient database for nursing that specializes in nursing in the psychiatric hospital in Japan. Therefore, psychiatric nursing care assessment is inefficient. The Japanese Psychiatric Nursing Assessment Classification System (PsyNACS)@ was developed to improve psychiatric nursing care services [4]. The PsyNACS $\odot$ has nine Patient Assessment Data (PAD) with 2 to 5 Cluster Assessment Data (CAD). Thirty one CADs comprised the Patient Assessment Data: (PAD1) Psychological symptom and stress, (PAD2) Information about treatment, (PAD3) Function of eating and balance of water, (PAD4) Life and value, (PAD5) Vital signs and health assessment, (PAD6) Self-care, (PAD7) Social Support, (PAD8) Activity, sleeping and mobility capability, and (PAD9) Sexual function and sexual behavior. The PsyNACS $\odot$ is a classification of items assessing health care needs within the Japanese psychiatric nursing care environment. It can also be used in various psychiatric patient care situations in psychiatric units.

Psychiatric hospitals in Japan have many types of units, such as the Acute Care Units (ACU), General Care Units (GCU), wherein patients whose conditions become stable are admitted for functional maintenance and recovery prior to being discharged, Long-term Care Units (LCU), Physically Complicated Disease Care Units (CDCU) and Dementia Care Units (DCU) [5]. In order to respond to the needs of psychiatric patients based on social backgrounds, medical treatments, nursing care, and post-discharge rehabilitation, prioritized assessment of patient conditions in specific psychiatric units is essential. Effective and good nursing-care can be provided through focused assessment of patients through the use of the PsyNACS $\odot$ within each psychiatric practice unit.

The aim of this study is to determine the priority Cluster Assessment Data (CAD) of each of the Patient Assessment Data (PAD); (PAD1) Psychological symptom and stress, (PAD2) Information about treatment, (PAD3) Function of eating and balance of water, (PAD4) Life and value, (PAD5) Vital signs and health assessment, (PAD6) Self-care, (PAD7) Social support, (PAD8) Activity, sleeping and mobility capability, and (PAD9) Sexual function and sexual behavior of the PsyNACS@ for each type of psychiatric unit.

\section{Methods}

\subsection{Selection of Hospitals and Respondents}

Selection of hospitals included psychiatric general care unit and long term care units, and a plurality of unit functions were selected. Psychiatric units in general hospitals which included various treatments other than psychiatric units were excluded.

The respondents were experienced psychiatric nurses who were employed by single psychiatric hospitals with 200 or more beds. They were from the ACU, GCU, LCU, CDCU, and DCU in their respective hospitals. In addition, these nurses must have had clinical experiences of more than 5 years as professional nurses, and with clinical experiences in psychiatric units of not less than three years (excluding licensed practical nurse). The 
subjects were chosen as recommended by the hospital administrators.

The managers of the psychiatric units were contacted to facilitate the dissemination of the information. The information packet was prepared and mailed to them. The survey information included reasons for the study and for participation in the on-line survey using Survey Monkey@ conducted within a three-month period, from February to April 2015.

\subsection{Data Analysis}

The collection of data used the PsyNACS $\odot$ Questionnaire and the Demographic Data Sheet. The Demographic Data sheet required respondents to provide their personal data, e.g. age, gender, place of work, years of experience as a nurse in general and years of experience in Psychiatric Units, etc. Educational attainment was not included.

PsyNACS $\odot$ is composed of three sections: The general data set composed of nine Patient Assessment Data (PADs), with each PAD having 2 to 5 Cluster Assessment Data (CADs). There were thirty-one CADs which were comprised of selected items. The "level of importance" for each item was evaluated using a Likert scale: (1 point) Unnecessary, (2 points) Quite important; (3 points) with the following valuations Important; and (4 points) Very important. Mean factor points (MFP), derived from the total score factor divided by number of items, was calculated. The average of three points or more of the evaluation of the respondents indicate that the CAD was evaluated as "important" by the professional psychiatric nurses. Considering each of the practice units, the "level of importance" of each CAD that was evaluated by the practicing professional psychiatric nurses were grouped into five practicing units. Subsequently, the data were subjected to Welch's ANOVA to establish the priority of the CAD according to the unit functions. The Welch's ANOVA procedure is frequently recommended as the major alternative to the ANOVA F test [6]. Welch's ANOVA is a form of one-way ANOVA that does not assume equal variances. This study had five groups: ACU, GCU, LCU, CDCU, and DCU. The minimum sample size required were only 75 subjects with each group having at least 15 subjects. There were 435 subjects with valid responses thereby meeting the number of subjects required for performing Welch's ANOVA as a non-parametric test. The significant difference was observed in items by using the Tamhane's test as post hoc tests. For all analyses, the statistical significance was established at 0.05 level. All statistical analyses were performed using the SPSS for Windows software (version 20.0; SPSS Inc., Chicago, IL).

\subsection{Ethical Considerations}

This research study was approved by the University of Tokushima Hospital Clinical Study Ethical Review Board. Return of the survey implied that the subjects gave consent to participate in the study, who were notified that privacy would be protected.

\section{Results}

\subsection{Characteristics of Respondents}

The questionnaire was sent to 644 psychiatric professional nurses in Japan, but only 435 valid responses were received (response rate was 67.5\%). The respondents' age, clinical experiences as a nurse, experience in psychiatric nursing, and type of unit functions that respondents were working are shown on Table 1.

\subsection{Comparison of "Levels of Importance" of Each Patient Assessment Data (PAD) by Practice Unit Functions}

The analytical results of the comparison of "levels of importance" of each PAD by practice unit functions are shown in Table 2.

PAD1 scores for "Psychological symptom" in ACU (3.29 $\pm 0.47, \mathrm{p}<0.05)$, GCU $(3.19 \pm 0.38, \mathrm{p}<0.05)$ and LCU (3.17 $\pm 0.53, \mathrm{p}<0.05)$ were significantly higher than those in DCU $(2.93 \pm 0.52)$. Stress and coping scores for those in the ACU $(3.49 \pm 0.44)$ was significantly higher than that in CDCU $(3.25 \pm 0.44, \mathrm{p}<0.05)$. The score of "Mood disorder and aggression" in ACU (3.58 \pm 0.43$)$ was significantly higher than those in CDCU (3.34 \pm 0.45, $\mathrm{p}<0.05)$ and DCU $(3.38 \pm 0.46, \mathrm{p}<0.05)$.

In PAD2, the score "Information of adherence" in ACU $(3.47 \pm 0.34)$ was significantly higher than that in the DCU $(3.27 \pm 0.39, \mathrm{p}<0.05)$. Blood tests showed no significant difference was observed among them. 
Table 1. Characteristics of respondents $(\mathrm{N}=435)$.

\begin{tabular}{|c|c|c|c|c|}
\hline & Mean & SD & Min & Max \\
\hline Age (years) & 44.55 & 7.50 & 26 & 62 \\
\hline Clinical experience as nurse (years) & 20.40 & 8.20 & 5 & 47 \\
\hline Clinical experience in psychiatry nursing (years) & 17.08 & 8.01 & 3 & 47 \\
\hline The types of unit functions & & & $\mathrm{n}$ & $\%$ \\
\hline Psychiatric acute care unit & & & 109 & 25.06 \\
\hline Psychiatric general care unit & & & 75 & 17.24 \\
\hline Psychiatric long term care unit & & & 134 & 30.80 \\
\hline Complicated disease care unit & & & 51 & 11.72 \\
\hline Dementia care unit & & & 66 & 15.17 \\
\hline
\end{tabular}

$\mathrm{SD}=$ Standard Deviation, Min = Minimum, Max $=$ Maximum.

In PAD3, the score for "Function of eating" in CDCU (3.43 \pm 0.38$)$ was significantly higher than those in LCU (3.25 $\pm 0.37, \mathrm{p}<0.05)$ and GCU (3.21 $\pm 0.36, \mathrm{p}<0.05)$. The score of "Function of eating" in DCU (3.44 \pm $0.43)$ was significantly higher than those in LCU $(3.25 \pm 0.37, \mathrm{p}<0.05)$ and GCU $(3.21 \pm 0.36, \mathrm{p}<0.05)$. The score of "Excretion situation" in CDCU (3.16 \pm 0.42$)$ is significantly higher than that in LCU $(2.94 \pm 0.40, \mathrm{p}<$ $0.05)$. The scores of "Balance of water" in GCU (3.37 $\pm 0.44, p<0.05)$, ACU $(3.34 \pm 0.45, p<0.05)$ and LCU (3.26 $\pm 0.46, \mathrm{p}<0.05)$ were significantly higher than that in DCU $(3.05 \pm 0.50)$.

In PAD4, the scores of "Intention/point of view" were more than three points in ACU, GCU and LCU, and these were at a level of two points (Quite important) in the other practice unit functions. However, there was no significant difference reached.

In PAD5, the score of "General health condition" in CDCU $(3.35 \pm 0.37)$ was significantly higher than the scores obtained in the ACU $(3.16 \pm 0.35, \mathrm{p}<0.05)$ and GCU $(3.12 \pm 0.39, \mathrm{p}<0.05)$. The score of "Respiratory and chest symptom" in CDCU (3.18 \pm 0.48$)$ was significantly higher than those in ACU (2.82 $\pm 0.50, \mathrm{p}<0.05)$, LCU $(2.78 \pm 0.49, \mathrm{p}<0.05)$ and GCU $(2.76 \pm 0.51, \mathrm{p}<0.05)$, and DCU $(2.99 \pm 0.49)$ was significantly higher than LCU $(2.78 \pm 0.49, \mathrm{p}<0.05)$. The score of "Vital signs" in CDCU $(3.32 \pm 0.43)$ was significantly higher than those in LCU $(3.05 \pm 0.36, \mathrm{p}<0.05)$ and GCU $(3.01 \pm 0.42, \mathrm{p}<0.05)$.

In PAD6, the scores of "Activity of daily living (ADL)" in GCU (2.91 $\pm 0.45, \mathrm{p}<0.05)$, ACU (2.85 $\pm 0.43, \mathrm{p}<$ $0.05)$ and LCU $(2.82 \pm 0.45, \mathrm{p}<0.05)$ were significantly higher than those in CDCU $(2.53 \pm 0.59)$. The scores for ADL in GCU ( $2.91 \pm 0.45)$ was significantly higher than those in DCU $(2.64 \pm 0.61, \mathrm{p}<0.05)$. The score of "Appearance" in GCU ( $2.83 \pm 0.39, \mathrm{p}<0.05)$ was significantly higher than those in CDCU $(2.63 \pm 0.35)$.

In PAD7, the score of "Relationship to the health care providers" in ACU (3.27 \pm 0.40$)$ was significantly higher than those in DCU $(3.05 \pm 0.49, \mathrm{p}<0.05)$. However, the score of "Relationships with others" in ACU $(3.40 \pm 0.45)$ was significantly higher than those in the CDCU $(3.12 \pm 0.48, \mathrm{p}<0.05)$.

In PAD8, the score of "Mobility capability" in the DCU $(3.31 \pm 0.47)$ was significantly higher than those in the LCU $(3.12 \pm 0.34, \mathrm{p}<0.05)$.

In PAD9, the scores of "Interest toward sexuality" in ACU (2.69 $\pm 0.43, \mathrm{p}<0.05)$, GCU $(2.68 \pm 0.49, \mathrm{p}<$ $0.05)$ and LCU $(2.61 \pm 0.47, \mathrm{p}<0.05)$ were significantly higher than those in the DCU $(2.33 \pm 0.67)$. The score of "Sexual function" in ACU (2.95 \pm 0.47$)$ was significantly higher than those in LCU $(2.76 \pm 0.55, \mathrm{p}<0.05)$, CDCU (2.39 $\pm 0.76, \mathrm{p}<0.05)$ and DCU $(2.08 \pm 0.96, \mathrm{p}<0.05)$. The scores of "Sexual function" in LCU $(2.76 \pm$ $0.55, \mathrm{p}<0.05)$ and GCU $(2.73 \pm 0.67, \mathrm{p}<0.05)$ were significantly higher than those in the DCU $(2.08 \pm 0.96)$. Similarly, the score in the LCU $(2.76 \pm 0.55)$ was significantly higher in the CDCU $(2.39 \pm 0.76, \mathrm{p}<0.05)$.

\section{Discussion}

The assessment priorities for each of the types of units and associated 'important' factors vary by unit. The following will be discussed in each unit function.

\subsection{Assessment Items Priority in the ACU}

Psychological symptom, Stress coping, Mood disorder and aggression, Information of adherence, Information of 


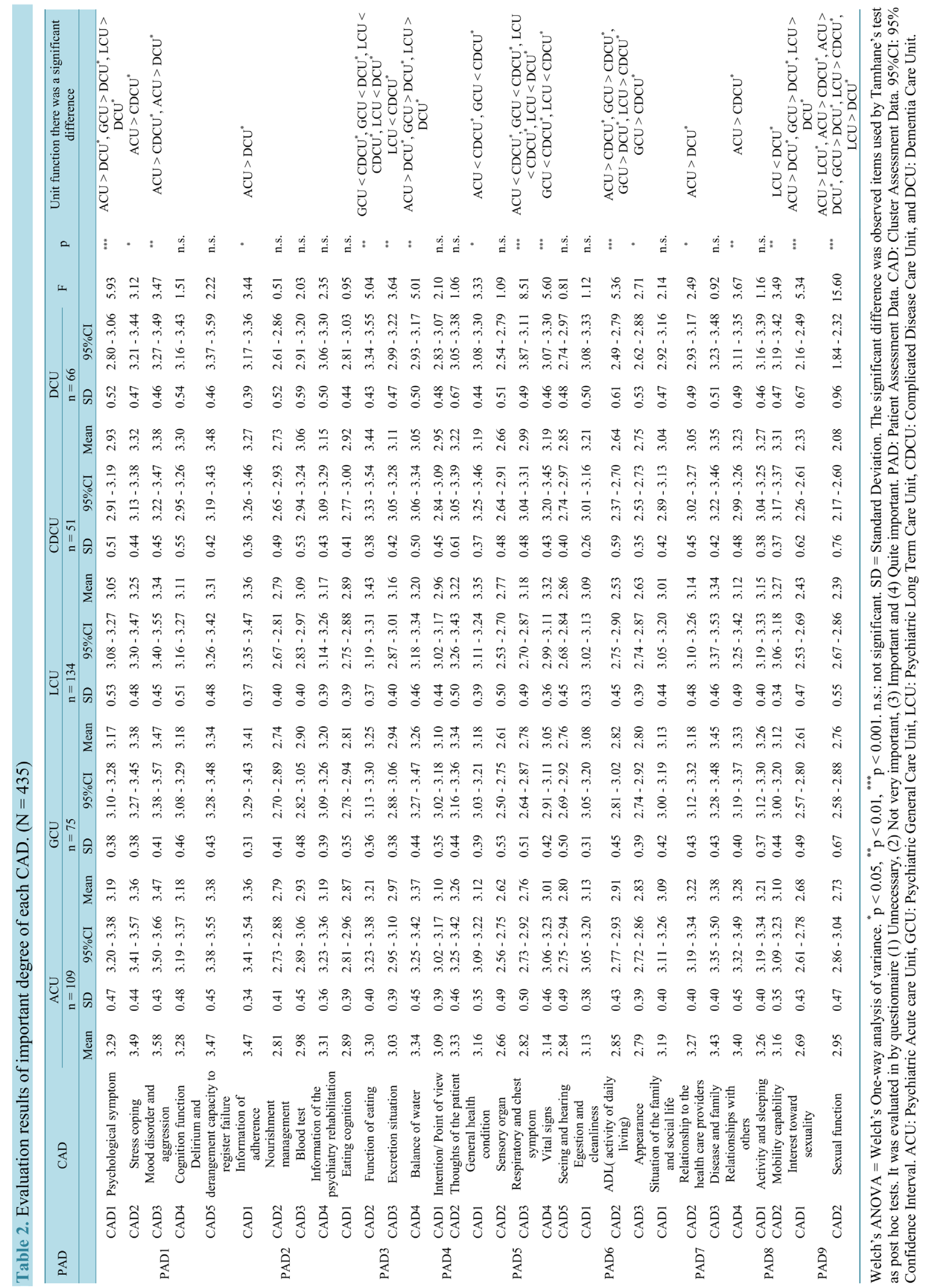


the psychiatry rehabilitation, Situation of the family and social life, Relationship to the health care providers, Relationships with others were evaluated as significantly "important".

The study by Bowers [7], support the factors identified as being important roles of nurses in ACU. These are "providing safety for the patient and others, collecting and communicating information about patients, giving and monitoring treatment, tolerating and managing disturbed behavior, providing personal care, and managing an environment where patients can comfortably stay”. In order to carry out these case-by-case cares, it is required in the ACU that nurses promptly assess the present condition of the patient and perform necessary nursing care [8]. For that purpose, it was considered to be necessary to acquire the information concerning the patient's ability to understand, the developmental stage, current treatment performed, and any relapsing condition of the psychiatric disease.

In addition, "Situation of the family and social life" has been evaluated as important. It was inferred that psychiatric nurses believe it is important to work towards the rehabilitation from the stage of the acute phase in Japan.

Regarding "Relationship to the health care providers" in ACU was higher than that in DCU and was significantly higher than that in the CDCU. As these factors concern the patients' involvement in society, they were very important information for supporting the discharge of the patients. For discharge support for the individual with mental illness, it is necessary to develop a community environment with health care providers and social workers and good supporters [9]. Therefore, in this study, it is inferred that recently, in psychiatric hospitals in Japan positive results were seen in moving patients to the community.

However, Tanioka et al. [10] have described that patient discharge to home will be possible not only with the willingness of the health care provider and patient, but also of the family's preparedness to receive the patient. Kayama et al. [3] explained that, as a reaching out approach, in Japan, it is the intervention in family and the prevention against worsening physical symptom that caused the reduction of re-hospitalization. According to a study by Nakanishi et al. [11], nurses' involvement in patients in making the plan of discharge since the acute care period caused the decline of the rate of re-hospitalization. The information of discharge support is considered to be important, one that exerts an influence on the actual situation of Japan.

\subsection{Assessment Items Focused in the GCU}

The scores of "Balance of water" in GCU, ACU and LCU were significantly higher than that in DCU. Dehydration is the most common fluid and electrolyte imbalance, concern in the elderly patients. Nurses have to identify the risk of dehydration in older patients [12] [13]. In addition, psychiatric patients may be more at risk of cardiovascular complications, such as QT interval prolongation. This risk can occur with both first- and second-generation antipsychotics. Electrolyte disturbances may increase this risk potential [14]. Also, it was considered that the disturbance in "Balance of water" is caused by conditions involving whole-body management in the acute period and the internal use of antipsychotic drugs in the long term, thereby affecting the assessment values [15] [16]. Therefore, "Balance of water" was more important than other practice unit functions.

\subsection{Assessment Items Focused in the LCU}

Intention/point of view, thoughts of the patient, disease and family was found "important" more frequently than any of the other practice unit functions.

As a function of the practice unit that is focused on prolonged hospitalization, the care in the LCU is directed towards supporting the impending discharge of the patient. In there, nurses must provide care with an emphasis on social resources and respect for the patient's way of living through interdisciplinary cooperation [17] [18]. The patient's thoughts and family involvement is important as was suggested in the study results [10] [19].

\subsection{Assessment Items Focused in the CDCU}

Excretion situation, general health condition, respiratory and chest symptom, and vital signs were evaluated as "important" more frequently than the other practice unit functions. The score of "blood test" did not show significantly different among the units. In CDCU and DCU were more than three points. However, in other unit functions were in the level of two points. Because the patients are having psychiatric symptoms without physical complications, the frequency of venous blood collection was low, influencing the evaluation of the activity as not as an important assessment data than in the other practice units. 
However, psychiatric nurses have to pay attention to the blood data in the nursing care, it is estimated that physical complications will increase due to changing demographics caused by the aging population in Japan [20] [21].

The score of "Excretion situation" was higher than that in the LCU, as it includes the items concerning the symptom and property at the time of excretion. It is considered to be an observational item necessary for the assessment of physical symptoms.

As for the score of "general health condition" of PAD5 in the CDCU, this was found higher for these patients than those from ACU and GCU. Under the medical-fee schedule, as complications including pneumonia are included in the requirements for admission to a physical complication, these patients are usually admitted in CDCU. "General health condition" includes the items of "ileus", "abdominal conditions" and "signs of infection". These physical complications often occur in patients with schizophrenia [22]. Therefore, it is often inferred that physical findings are regarded to be more important in CDCU than in other unit functions.

The score of "respiratory and chest symptom" in the CDCU was higher than those in ACU, LCU and GCU. According to the study by Brunnstrom et al. [23] in Sweden, the cause of death of 524 patients with dementia (45.8\%) was respiratory-related diseases. The score of "vital signs" in the CDCU was higher than those in the LCU and the GCU. The factor of "vital signs" includes the items of body temperature, pulse and blood pressure, and is also considered to be important for the assessment of patients in CDCU. However, the scores of the factors of "vital signs" and "respiratory and chest symptom" in ACU, LCU and GCU were low. This is because in these practice units, it was considered that if a complication worsens, patients are moved to the CDCU or general hospital where somatic therapy is possible, therefore, these factors are not regarded as important [24]. Findings of this study, CDCU considered to "general health condition" have been important in comparison with the other unit.

Viewed from the perspective of Japanese insurance system, DCU is not fee-for-service reimbursement system. If patient has complication disease, it was considered such patient has been moved to another unit (fee-forservice reimbursement system).

\subsection{Assessment Items Focused in the LCU}

"Cognition function", "delirium and derangement capacity to register failure”, "function of eating”, "egestion and cleanliness", "activity and sleeping”, "mobility capability” were evaluated significantly more important than other practice unit functions. The score of "function of eating" in DCU was higher than those in LCU and GCU. These factors include the items concerning accidental ingestion caused by peripheral symptoms and lowering motivation due to dementia. Due to the aggravation of symptoms and the increase of respiratory complications such as accidental ingestion and pneumonia caused by aging, this factor is considered to be regarded as important [25]. It is frequently inferred that many elderly with pneumonia caused by accidental ingestion are admitted in the CDCU; because of this, "function of eating" has become a very important assessment item in the DCU.

"Mobility capability" in DCU was significantly higher than that in LCU. "Mobility capability", in particular, includes the items concerning falls. The risks of slipping and falling are not caused only by psychiatric symptoms as shown by previous research that every antipsychotic drug increases the risk of patients slipping and falling 2.63 times because of the side effect of the medications [26]. Stenhagen M. et al. [27] explained that the lowering of cognition function and the condition of instrumental activities of daily living caused by aging are related to the risks of slipping and falling. In order to prevent tumbling, the observation of gait and the provision of appropriate moving instrument are required. According to the study by Soderqvist A. et al. [28], the assessments of "cognition function" by nurses were lower than actual conditions. Psychiatric hospitals are considered to put emphasis on the risk assessment for tumbling and falling with the advancement of aging society [27] [28].

\subsection{The Difference of the Importance in CAD between the Various Practice Units}

The scores of "ADL" in GCU, ACU and LCU were higher than that of CDCU, and score in GCU was higher than that in DCU. Support after discharge is important in the psychiatric care of patients in Japan and "ADL" was considered to be an item necessary for patients to live better and healthy lives in the community after discharge [29]-[31]. In psychiatric hospitals in Japan, GCU and LCU are often in charge of supporting patients for discharge. It can be inferred that as the CDCU has the role of improving the symptoms of pneumonia and other previous maladies or sickness in a prior stage, the necessity of ADL observation was regarded lower in most of 
the practice units. The scores of "appearance" in GCU and LCU were higher than that in CDCU.

As with the case of ADL, it is considered that Appearance is directly linked to the assessment of patients' living ability after discharge; therefore, its scores in GCU and LCU were higher.

The scores of "interest toward sexuality" in ACU, GCU and LCU were higher than that in DCU. The score of "sexual function" in ACU was higher than those in LCU, CDCU and DCU. The score of sexual function in LCU and GCU were higher than that in DCU, and the score of sexual function in LCU was higher than that in CDCU. However, both "interests toward sexuality" and "sexual function" were assessed only as "quite important" in all unit functions, and both were scored lowest in the DCU, in particular. Antipsychotic drug has been associated with increased global side effect burden, rates of Parkinsonian side effects, anticholinergic use, hyperprolactinemia, sexual dysfunction, hypersalivation, sedation/somnolence, cognitive impairment, and diabetes [32]. Although the event concerning sexuality tends to be considered less serious in the hospital than in community society, "interest toward sexuality" has been regarded as important not only for the young, but also the elderly, therefore, it is necessary to place importance on it in the future. Sexual behavior problems sometimes occur because of erroneous judgment placed on its importance owing to the psychiatric symptoms in psychiatric units. According to the study by Steven et al. [33], many of the patients with chronic psychiatric disease were sexually active, therefore it is important that sexuality is considered "important" in planning nursing care of psychiatric patients in all practice units [34].

\section{Implications}

This study was focused on determining the PAD for specific units of psychiatric patients as evaluated by psychiatric nurses who practice in specific psychiatric units. The level of accuracy of the results of the study concerning the information necessary for the assessment of patients was considered to be high. Because the nursing care data base corresponding to the particularity of each practice unit function was clarified, early interventions of patients according to each unit function can be possible. It is considered that nurses can exert influences on timely and effective interventions regarding quality of life of patients in psychiatric units and the resolution to the problem of prolonged hospitalization.

\section{Limitations}

In this study, the survey did not include psychiatric nurses of children and minors. Therefore, the assessment and nursing care implications derived from the database cannot be used for these types of patient populations. Similarly, only professional nurses who worked in psychiatric hospitals with 200 or more beds were considered for the study.

\section{Conclusion}

Each of the Cluster Assessment Data (CAD) of the nine PADs ware established according to functions and practice area/unit. It was revealed that psychiatric hospitals in Japan distinctively specify assessment foci according to functional areas. By prioritizing the CAD, more effective and efficient assessments can be performed. The following are evaluated "important' in the ACU: Psychological symptom, stress coping, mood disorder and aggression, information of adherence, information of the psychiatry rehabilitation, situation of the family and social life, relationship to the health care providers, relationships with others; in the GCU, balance of water, while in the LCU, these include intention/point of view, thoughts of the patient, disease and family. In the CDCU, blood test, excretion situation, general health condition, respiratory and chest symptom, vital signs; while in DCU, cognition function, delirium and derangement capacity to register failure, function of eating, egestion and cleanliness, activity and sleeping, mobility capability. Through manipulation of practice priority areas, PsyNACS $\odot$ can be made to enhance the nursing care of psychiatric patients by prioritizing the CAD for each PAD. In doing so, more effective and efficient assessments can be performed according to practice units. PsyNACS $\odot$ is more functional and valuable when PAD of the PsyNACS $\odot$ is designed and used in particular psychiatric practice unit.

\section{Acknowledgements}

We would like to express our deep gratitude to the Japanese psychiatric nurses and nursing administrators who 
participated in this study. And we also would like to express our deep gratitude to the academic supervisors.

\section{References}

[1] Organization of Economics and Development (OECD) (2014) Japan Trails Other Countries in “Deinstitutionalization”, But There Are Signs of Progress, Says OECD. http://www.oecd.org/els/health-systems/MMHC-Country-Press-Note-Japan.pdf

[2] Ministry of Health, Labour and Welfare Social and Assistance Stations Disorder Ministry of Health and Welfare (2011) Guidance of Persons with Mental Disabilities Outreach Promotion. (In Japanese). http://www.mhlw.go.jp/bunya/shougaihoken/service/dl/chiikiikou_03.pdf

[3] Kayama, M., Kido, Y., Setoya, N., Tsunoda, A., Matsunaga, A., Kikkawa, T., et al. (2014) Community Outreach for Patients Who Have Difficulties in Maintaining Contact with Mental Health Services: Longitudinal Retrospective Study of the Japanese Outreach Model Project. BioMed Central Psychiatry, 14, 1-10. http://dx.doi.org/10.1186/s12888-014-0311-y

[4] Ito, H., Miyagawa, M., Ozawa, K., Tanioka, T., Yasuhara, Y., Kataoka, M., et al. (2015) The Development of the Japanese Psychiatric Nursing Assessment Classification System (PsyNACSC). Open Journal of Psychiatry, 6, 20-33. http://dx.doi.org/10.4236/ojpsych.2016.61003

[5] Tanioka, T., Kataoka, M., Yasuhara, Y., Miyagawa, M. and Ueda I. (2011) The Role of Nurse Administrators and Managers in Quality Psychiatric care. The Journal of Medical Investigation, 58, 1-10. http://dx.doi.org/10.2152/jmi.58.1

[6] Show, L.J. and Gwowen, S. (2013) Sample Size Determinations for Welch's Test in One-Way Heteroscedastic ANOVA. British Journal of Mathematical and Statistical Psychology, 67, 72-93.

[7] Bowers, L. (2005) Reasons for Admission and Their Implications for the Nature of Acute Inpatient Psychiatric Nursing. Journal of Psychiatric and Mental Health Nursing, 12, 231-236. http://dx.doi.org/10.1111/j.1365-2850.2004.00825.x

[8] Bowers, L., Simpson, A., Alexander, J., Hackney, D., Nijman, H., Grange, A. and Warren, J. (2005) The Nature and Purpose of Acute Psychiatric Wards: The Tompkins Acute Ward Study. Journal of Mental Health, 14, 625-635. http://dx.doi.org/10.1080/09638230500389105

[9] Kawamura, A., Tanioka, T., Tada, T., King, B. and Locsin, RC. (2013) Collaborative Agencies and Quality Discharge Support for the Long-Term Care Inpatients with Mental Illness. The Journal of Medical Investigation, 60, 52-60. http://dx.doi.org/10.2152/jmi.60.52

[10] Tanioka, T., Chiba, S., Onishi, C., Kataoka, M., Kawamura, A., Tomotake, M., et al. (2013) Factors Associated with Discharge of Long-Term Inpatients with Schizophrenia in Japan: A Retrospective Study. Issues in Mental Health Nursing, 34, 256-264. http://dx.doi.org/10.3109/01612840.2012.742602

[11] Nakanishi, M., Niimura, J. and Tanoue, M. (2015) Association between Length of Hospital Stay and Implementation of Discharge Planning in Acute Psychiatric Inpatients in Japan. International Journal of Mental Health Systems, 9, 1-8. http://dx.doi.org/10.1186/s13033-015-0015-9

[12] Davidhizar, R., Dunn, C.L. and Hart, A.N. (2004) A Review of the Literature on How Important Water Is to the World's Elderly Population. International Nursing Review, 51, 159-166. http://dx.doi.org/10.1111/j.1466-7657.2004.00224.x

[13] Hodgkinson, B., Evans, D. and Wood, J. (2003) Maintaining Oral Hydration in Older Adults: A Systematic Review. International Journal of Nursing Practice, 9, 19-28. http://dx.doi.org/10.1046/j.1440-172X.2003.00425.x

[14] Aghaienia, N., Brahm, N.C., Lussier, K.M. and Washington, N.B. (2011) Probable Quetiapine-Mediated Prolongation of the QT Interval. Journal of Pharmacy Practice, 24, 506-512. http://dx.doi.org/10.1177/0897190011415683

[15] Melissa, G. and MacDara, M. (2015) Psychogenic Polydipsia: The Result, or Cause of, Deteriorating Psychotic Symptoms? A Case Report of the Consequences of Water Intoxication. Case Reports in Psychiatry, 2015, Article ID: 846459, 3 p.

[16] Dundas, B., Harris, M. and Narasimhan, M. (2007) Psychogenic Polydipsia Review: Etiology, Differential, and Treatment. Current Psychiatry Reports, 9, 236-241. http://link.springer.com/content/pdf/10.1007\%2Fs11920-007-0025-7.pdf http://dx.doi.org/10.1007/s11920-007-0025-7

[17] Kataoka, M., Ozawa, K., Tanioka, T. and Locsin, R. (2015) Clarifying the Strengths-Oriented Attitude among Nurses in Psychiatric Hospitals in Japan. Health, 7, 776-787. http://dx.doi.org/10.4236/health.2015.76092

[18] Nagayama, Y. and Hasegawa, M. (2014) Nursing Care Process for Releasing Psychiatric Inpatients from Long-Term Seclusion in Japan: Modified Grounded Theory Approach. Nursing \& Health Sciences, 16, 284-290.

http://dx.doi.org/10.1111/nhs.12094 
[19] Kono, T., Shiraishi, H., Tachimori, H., Koyama, A., Naganuma, Y. and Takeshima, T. (2012) Discharge Dynamics and Related Factors of Newly-Admitted Patients in Psychiatric Hospitals. Psychiatria et Neurologia Japonica, 114, 764781. (In Japanese)

[20] Niimura, H., Nemoto, T., Sakuma, K. and Mizuno, M. (2011) Promoting “Successful Aging” in Community Psychiatric Care. Seishin Shinkeigaku Zasshi, 113, 380-386. (In Japanese)

[21] Aoyagi, Y. and Shephard, R.J. (2011) A Model to Estimate the Potential for a Physical Activity-Induced Reduction in Healthcare Costs for the Elderly, Based on Pedometer/Accelerometer Data from the Nakanojo Study. Sports Medicine, 41, 695-708. http://dx.doi.org/10.2165/11590530-000000000-00000

[22] Jimmi, N and Jonathan, M. (2012) Risk Factors for Ileus in Patients with Schizophrenia. Schizophrenia Bulletin, 38, 592-598. http://dx.doi.org/10.1093/schbul/sbq137

[23] Brunnström, H. and Englund, E. (2009) Cause of Death in Patients with Dementia Disorders. European Journal of Neurolog, 16, 488-492. http://dx.doi.org/10.1111/j.1468-1331.2008.02503.x

[24] Constantine, G. L., Gary, D., Michael, J.K. and William, R.B. (2002) Medical Comorbidity in Psychiatric Inpatients: Relation to Clinical Outcomes and Hospital Length of Stay. Psychosomatics, 43, 24-30. http://dx.doi.org/10.1176/appi.psy.43.1.24

[25] Nakajima, N., Aiba, M., Fukuda, Y., Boku, S., Isonuma, H., Tsuda, H. and Hayashida, Y. (2009) Causes of Death in Hospitalized Elderly Patients. Nihon Ronen Igakkai Zasshi (Japanese Journal of Geriatrics), 46, 71-78. (In Japanese) http://dx.doi.org/10.3143/geriatrics.46.71

[26] Sano, T., Harada, M., Sugawara, T., Isaka, N., Masuoka, A., Mikami, A., et al. (2013) Use of Psychotropics and the Risk of Falls in Hospitalized Psychiatric Patients. Yakugaku Zasshi, 133, 897-903. (In Japanese) http://dx.doi.org/10.1248/yakushi.13-00003

[27] Stenhagen, M., Ekström, H., Nordell, E. and Elmstahl, S. (2014) Both Deterioration and Improvement in Activities of Daily Living Are Related to Falls: A 6-Year Follow-Up of the General Elderly Population Study Good Aging in Skane. Clinical Interventions in Aging, 9, 1839-1846. http://dx.doi.org/10.2147/CIA.S70075

[28] Soderqvist, A., Stromberg, L., Ponzer, S. and Tidermark, J. (2006) Documenting the Cognitive Status of Hip Fracture Patients Using the Short Portable Mental Status Questionnaire. Journal of Clinical Nursing, 15, 308-314. http://dx.doi.org/10.1111/j.1365-2702.2006.01296.x

[29] Ponzetto, M., Maero, B., Maina, P., Rosato, R., Ciccone, G., Merletti, F., Rubenstein, Z.L., and Fabris, F. (2003) Risk Factors for Early and Late Mortality in Hospitalized Older Patients: The Continuing Importance of Functional Status. The Journals of Gerontology Series A, Biological Sciences, 58, M1049-M1054. http://dx.doi.org/10.1093/gerona/58.11.M1049

[30] Koolaee, K.A. and Falsafinejad, R.M. (2014) Effects of Communal Living Skills on Improving Activities of Daily Living of Male Patients with Schizophrenia. Journal of Schizophrenia Research, 1, 4.

[31] Barton, W.P., Robert, K.H., Julie, A.G., Jovier, D.E., Thomas, L.P., Shahrokh, G. and Dilip, V.J. (2002) Heterogeneity in Functional Status among Older Outpatients with Schizophrenia: Employment History, Living Situation, and Driving. Schizophrenia Research, 55, 205-215. http://dx.doi.org/10.1016/S0920-9964(01)00218-3

[32] Gallego, A.J., Nielsen, J., Hert, D.M., Kane, M.J. and Correll, U.C. (2012) Safety and Tolerability of Antipsychotic Polypharmacy. Expert Opinion on Drug Safety, 11, 527-542. http://dx.doi.org/10.1517/14740338.2012.683523

[33] Welch, S. and Clements, G. (1996) Development of a Policy on Sexuality for Hospitalized Chronic Psychiatric Patients. Canadian Journal of Psychiatry, 41, 273-279.

[34] Tanioka, T., Mano, M., Takasaka, Y., Tada, T. and Kawanishi, C. (2006) Challenge of Psychiatric Rehabilitation for Patients with Long-Term Hospitalizations Using the Nirje's Normalization Principles as a Valuation Standard: Two Case Studies. The Journal of Medical Investigation, 53, 209-217. http://dx.doi.org/10.2152/jmi.53.209 


\section{Submit or recommend next manuscript to SCIRP and we will provide best service for you:}

Accepting pre-submission inquiries through Email, Facebook, Linkedin, Twitter, etc A wide selection of journals (inclusive of 9 subjects, more than 200 journals)

Providing a 24-hour high-quality service

User-friendly online submission system

Fair and swift peer-review system

Efficient typesetting and proofreading procedure

Display of the result of downloads and visits, as well as the number of cited articles

Maximum dissemination of your research work

Submit your manuscript at: http://papersubmission.scirp.org/ 